\title{
Additive Manufacturing-Past, Present, and the Future
}

\author{
Markus Korpela, Niko Riikonen, Heidi Piili, \\ Antti Salminen, and Olli Nyrbilä
}

\section{INTRODUCTION}

Additive manufacturing (AM) is a relatively new manufacturing method that compiles different techniques to join materials together material on top of existing structure in order to make parts from 3D-model data-typically layer by layer. Additive manufacturing is a combination of

\footnotetext{
M. Korpela • N. Riikonen • H. Piili $(\square)$

Research Group of Laser Material Processing \& Additive Manufacturing, Department of Mechanical Engineering, LUT School of Energy Systems, LUT University, Lappeenranta, Finland e-mail: markus.korpela@lut.fi; niko.riikonen@lut.fi; heidi.piili@lut.fi
}
A. Salminen
Department of Mechanical Engineering, University of Turku, Turku, Finland e-mail: antti.salminen@utu.fi
O. Nyrhilä
EOS Finland Oy, Turku, Finland
e-mail: olli.nyrhila@eos.info
(C) The Author(s) 2020
M. Collan, K.-E. Michelsen (eds.), Technical, Economic and Societal
Effects of Manufacturing 4.0,
https://doi.org/10.1007/978-3-030-46103-4_2 
different technologies such as CAD (computer-aided design), CAM (computer-aided manufacturing), laser and electron energy beam technology, CNC (computer numerical control) machining, and laser scanning. Some of these technologies existed already in the 1950s, but only in the 1980s the maturity of the different technologies enabled the creation of additive manufacturing [1]. The term additive manufacturing substitutes historical terms, such as solid freeform fabrication, freeform fabrication, and rapid prototyping and it is also commonly called 3D-printing in nontechnical contexts and in colloquial language $[2,3]$.

Additive manufacturing was originally developed around polymers, waxes, and paper laminates and used predominantly for prototyping purposes, as the term "rapid prototyping" indicates [3]. First commercial systems were available already in the 1990s [4]. Nowadays, most additively manufactured parts are functional and many of them are made of more advanced materials such as ceramics, composites, or metals $[3,5,6]$. AM techniques have developed rapidly, enabling AM parts to be used even in the most highly regulated application areas, such as in aviation. The increase of interest on AM has risen due to the speedy development of the technologies involved and due to digitalization. The initial fast advances in technology were followed by a hype, when the expectations about the capabilities of the technology were drummed-up through the social media and through various non-technical evangelists.

The first three industrial revolutions changed the world permanently and were the result of findings by inventors such as James Watt and Thomas Edison. Figure 2 shows how number of equipment connected to internet has been growing during various industrial revolutions. Additive manufacturing has often been connected to the 4th Industrial Revolution (IR4), which is claimed to have started after the year 2000. IR4 is merely about the digitalization and the networking of various technologies. The IR4 is a result of various technologies being mature for new tasks around the same time and the fact that high speed data-transfer and enormous (compared to previous times) computer capacity is available. The major technologies involved in IR4, like augmented reality, additive manufacturing, and artificial intelligence are studied by various companies ranging from retail to manufacturing and from transportation to banking [7]. European Patent Office made a study about patents and IR4 and found that the number of patents filed related to the IR 4 increased with 54 percent in the past three years [8]. The number of patents in additive manufacturing has grown from few applications in 1991 to a "five hundred per year"-level in 2015, the growth in the number of patents is approximately 150 per year. Interestingly, only a fraction $(3.5 \%)$ of the filed patents were 


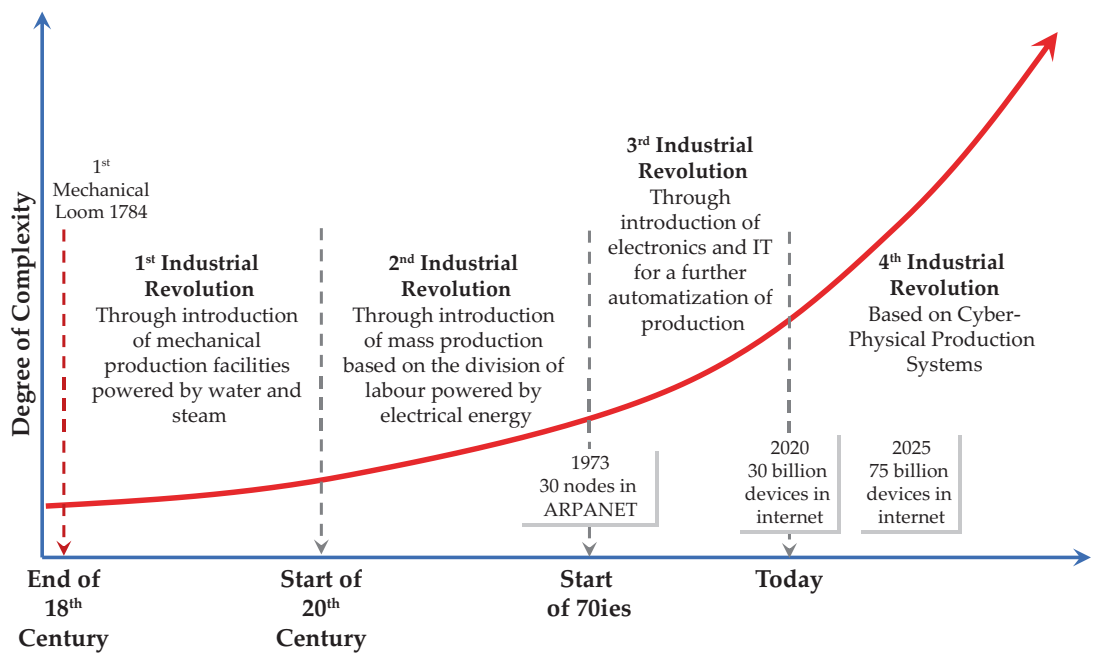

Fig. 1 The past and current industrial revolutions from the lst to the 4 th, and the number of devices connected to the Internet [10-12]

directly connected to IR4 main constituents-digitization and networking [1]. The IR4 and so-called smart factories are considered to be crucial game changers for the survival of US and European industries because they have the ability to reset the labor productivity back on the growthpath again [9]. The past and current industrial revolutions from the lst to the 4 th, and the number of devices connected to the Internet is presented in Fig. 1.

Main advantages of AM are connected to the ability to manufacture complex geometries [13], lighter structures, and the ability to allow customization. In subtractive manufacturing processes, an increase to the volume of material removed from the billet or an increase in the geometric complexity of the design cause the manufacturing time to be longer and the manufacturing costs to be higher. This often leads to components having excess material that cannot be cost-effectively removed [14]. Often the majority of removed material in conventional manufacturing ends up as waste [15], of which most can be recycled, but the value of this waste is typically just a fraction of the value of the original material. In additive manufacturing processes, complexity itself does not add costs in the same way and the material is added primarily only to where it is needed-thus parts are lighter by default. As an automated manufacturing process, AM shares similarities with CNC machining. It cannot currently add material 
faster than high-speed CNC machining can remove it, but it can manufacture more complex parts in a single-step process within a certain framework [3]. As a limitation, AM suffers from surface integrity on specific surfaces and of a degraded dimensional control [16], which often leads to the need of post-processing, especially in metal additive manufacturing. Attempts to solve this problem have been made via using hybrid systems that combine AM and CNC machining, but utilization level of these systems is typically very low in the industry (Fig. 2).

The field of additive manufacturing is suffering from a lack of standardization, because most already existing standards cannot be utilized in AM $[3,4]$, furthermore the technologies are developing so rapidly that standardization cannot keep up. The already existing non-AM standards rest on known homogeneous microstructures of standard bulk materials. This does not apply to AM, in which the microstructure, created during the process can vary within a part and depends on the used process parameter

Fig. 2 Macro images

of an additively manufactured (L-PBF), $10 \times 10 \times 10 \mathrm{~mm}^{3}$, tool-steel cube (a) showing geometrical inaccuracy, and (b) showing height differences on the surface and distortion in the left upper corner of the side of the cube

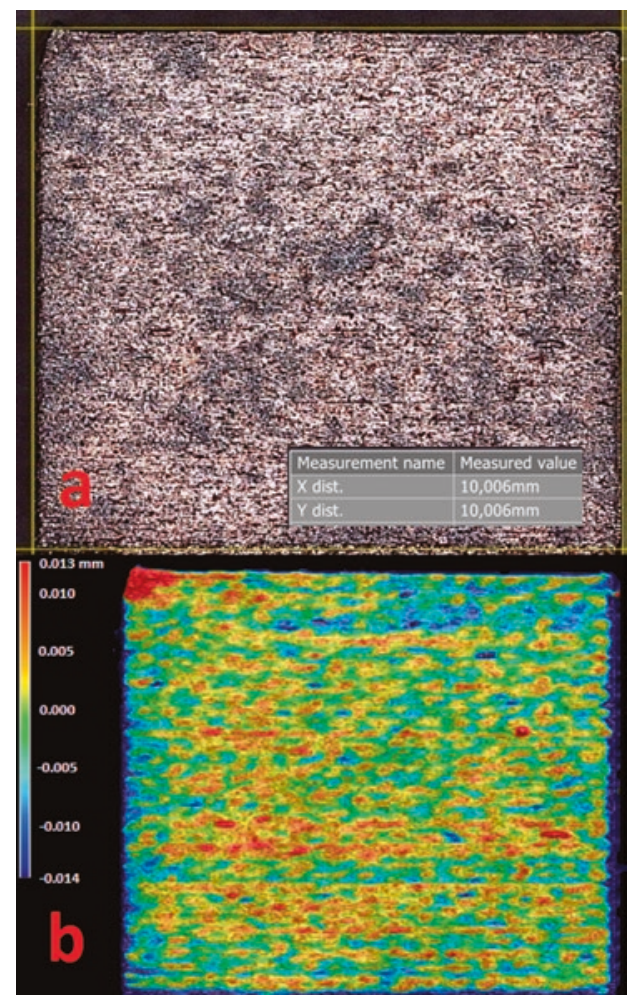


values. Tens, or possibly more than a hundred, different national and international AM standards have been approved, but additive manufacturing as a manufacturing method consists of thousands of different materials from polymers to metallic shape-memory alloys. As a reference, it took about 20 years to publish main European standards related to only aluminum in the context of conventional manufacturing [17].

\section{Additive Manufacturing Materials AND PROCESSES}

It was estimated in 2004 [18] that exist 40000 to 80000 engineering materials, and at least a thousand different processing methods for them. Just to point out, more than 20000 different steel alloys are available [19]. The range of materials available for AM is only a fraction of the total range [20] despite the high speed of material development. The development of a new material is feasible, if an application or the potential for a new material has been recognized and evaluated such that it covers the material development cost. In AM, and especially in metal AM, absolute material costs are low due to low production volumes and therefore savings in material costs play a relatively minor role. This slows down materials development, but the narrow material-repertoire is caused also by the short history of AM. Most of the research so far has been concentrating on the manufacturing of existing and approved materials with the idea to make them also suitable for manufacturing with AM [21]. The basic material development in AM usually means that the process is defined such that reliable production with a material can be guaranteed. The current development of AM materials is typically based on the use of conventional alloys that (already) exist for traditional manufacturing [22]. About 2800 different commercial AM materials are available today [51]. It is notable that commercial materials include "multiples of the same materials" with a different names or brands by different manufacturers. For example, there are multiple choices for stainless steel AISI $316 \mathrm{~L}$ as each manufacturer has their own name for it.

The materials development in AM can be seen in light of two different approaches - in the first approach an AM process for a traditional engineering material is developed such that the AM material properties correspond to traditional material properties as closely as possible-in the second approach the characteristics of an AM process are utilized to 
produce such materials that are only available for AM. For example, there is a possibility to create new characteristics for engineering materials, such as an optimized micro-structure for metal materials in a powder-bed fusion (PBF) process $[10,22-24]$. The development of AM specific alloys shows the interesting potential of AM for the future. The aluminum-alloy "Scalmalloy" is an example of such a developed alloy for which the mechanical properties are enhanced to fit the typical thermal cycle of laser based powder bed fusion (L-PBF) $[25,26]$.

Systematic knowledge about the properties of metal AM parts is missing and the repertoire of available materials is still limited [23, 27, 28] mainly to different stainless- and tool-steels, aluminum- and titaniumalloys, nickel-based superalloys, and cobalt-chromium alloys, consisting of about 30 different materials in total [29]. A study of Herzog et al., [21] covered 159 references of metal additive manufacturing with PBF and directed energy deposition (DED) processes. Their comprehensive analysis resulted that static and fatigue strength together with other mechanical properties of AM materials are alike to their conventional counterparts and that AM metals and alloys can be evaluated by known concepts of fracturemechanics [21]. Copper and some copper alloys have already become available, but are unfortunately not on the same maturity-level as the above-mentioned materials, due to their material property related issues such as low absorption of current laser beam wavelengths and especially high thermal conductivity, [30]. As non-engineering materials, some precious metals, such as gold and silver, are available as well. Similar materialdatabases that are available for conventional materials do not exist for additively manufactured materials, and the properties of the printed materials are neither discussed deeply in recently published books in the field of metal additive manufacturing [3, 27, 31, 32]. AM materials from the material research point of view are discussed deeper elsewhere in this book.

Tens or even hundreds of different AM-techniques exist, but EN, ISO, and ASTM approved standards categorize them into seven different process-categories. The process categories are listed in Table 1.

In metal AM, directed energy deposition (DED), powder bed fusion $(\mathrm{PBF})$, and sheet lamination are single-step processes in which basic material properties, such as density of more than $90 \%$, are achieved in a single operation step. Material extrusion and binder jetting of metal parts are multi-step processes in which the parts require consolidation by a secondary process such as sintering in an oven, in order to result density greater 
Table 1 Process categories of additive manufacturing, with definitions according to EN ISO/ASTM 52900 [2]

\begin{tabular}{ll}
\hline Process category & Definition: \\
\hline & "An additive manufacturing process in which ..." \\
Material extrusion & "... material is selectively dispensed through a nozzle or orifice" \\
Powder-bed fusion & “... thermal energy selectively fuses regions of a powder bed" \\
Binder jetting & “... a liquid bonding agent is selectively deposited to join powder \\
& materials" \\
Vat photopolymerization & “... liquid photopolymer in a vat is selectively cured by light \\
& activated polymerization" \\
Material jetting & "... droplets of build material are selectively deposited" \\
Directed energy & "... focused thermal energy is used to fuse materials by melting as \\
deposition & they are being deposited" \\
Sheet lamination & "... sheets of material are bonded to form a part" \\
\hline
\end{tabular}

than $90 \%$. Material jetting of metal parts is a rare production method, but at least one system manufacturer has established a machine for that purpose. According to the manufacturer, their process is a single-step process[33]. Different kinds of applications of different additive manufacturing processes can be seen in Fig. 3 [2, 27].

Out of these seven process categories, powder-bed fusion has shown the highest potential in additive manufacturing of metal parts, and in more detail, the PBF process that utilizes laser beam as a heat source [32]. It is also the most studied AM technique [16].

\section{Metal Additive Manufacturing}

Metal additive manufacturing is a over 30 years old manufacturing method [34] which has now grown to a point, where it is a potential method of manufacturing for real-world applications. Parts manufactured with the most common and widely applied metal additive manufacturing processes are only semi-finished, but in some cases, they can be used directly as endproducts $[32,35,36]$. Metal AM enables building of geometries that conventional subtractive manufacturing is not capable of [53].

Metal AM is still a niche market in manufacturing, but it is growing at a fast pace. Current systems of metal additive manufacturing are not something to completely revolutionize way of manufacturing, or to completely replace traditional manufacturing methods. AM is an addition to the repertoire of manufacturing methods and more likely will replace other 


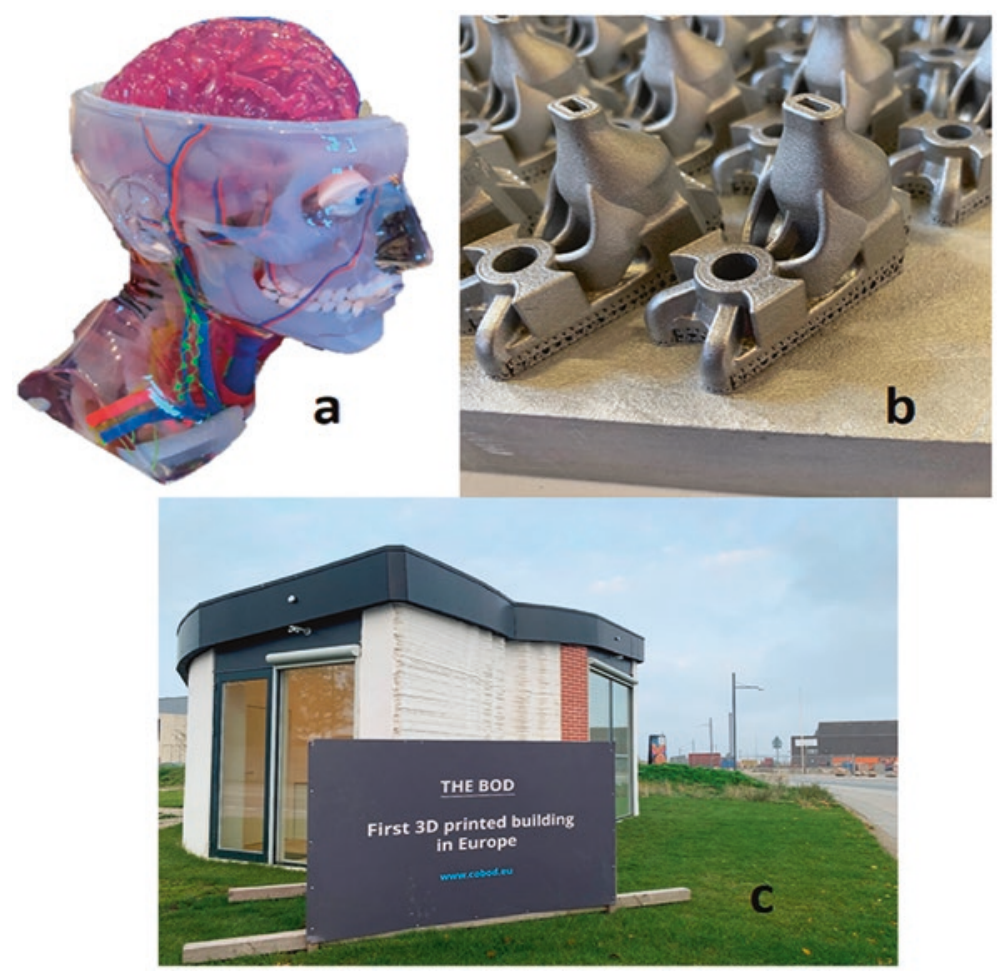

Fig. 3 Examples of additively manufactured objects with different AM processes; (a) human head- and brain-model made with material jetting, made out of polymers; (b) glue nozzles with complex geometry and inner structure, made with laser-based powder-bed fusion out of an aluminum-alloy, (c) exterior walls of what is claimed to be the first additively manufactured building in Europe-created with material extrusion out of concrete

manufacturing methods or manufacturing steps for certain applications. Despite the hype around additive manufacturing and its possibilities, metal AM has many restrictions that make it the most convenient choice of manufacturing for only a limited number of applications. This is due to the rather high costs (often $>1000 € / \mathrm{kg}$ for end-usable AM steel part) incurred by the required post-processing and the slow manufacturing speed of the rather expensive systems that need to be used. The applications that are economically viable to create by metal AM are typically (but 
not limited to) the size a human fist and geometrically (very) complex and if conventionally manufactured would require multi-step manufacturing processes such as machining, assembling, or joining. On the other hand, utilizing AM is beneficial for parts that have a geometry that typically requires casting, but for which the production volumes are low and would thus lead to rather high mold costs divided per unit-AM can be used to manufacture parts so complex that several casted parts would have to be joined to otherwise create them.

The layer-by-layer manufacturing method is not a new method for creating metal parts. It has been possible to cut holes to metal sheets and join them together via welding or by using fasteners for decades. This enables the same advantages as AM, such as possibilities to create complex geometries inside of a part. However, these kinds of sheet laminated applications have been very rarely utilized despite the opportunities they offer.

Despite the limitations and high expenses, utilization level of additive manufacturing is presumable lower than it could be. Certain parts, originally designed to be manufactured with subtractive manufacturing methods, could be more cost-effectively manufactured with AM, especially after redesigning these parts for AM-often such parts are still manufactured with conventional methods, lack of AM-knowledge might be one reason for the non adoption. Identifying parts suitable for AM requires lot of knowledge about the advantages and the disadvantages of metal additive manufacturing and experience about how to apply AM into industrial cases. This knowledge is not part of current engineering curricula so most engineers in the industry are not aware of it. Therefore, some companies have no knowledge about additive manufacturing, whilst some use it daily.

\section{Powder Bed Fusion}

This article deals mainly with laser based powder bed fusion, because it is the most common, widely applied, and possibly the most evolved metal additive manufacturing technology available $[27,32]$. It is also the most used metal AM technology for production of engineering components [27].

Powder bed fusion is based on melting metal powder to form parts layer-by-layer. The melting is based on melting of powder with electromagnetic radiation that is photons from a laser, or with electrons from an electron beam (EB). The laser beam is absorbed via Fresnell absorption, or plasma absorption, by the material both being relevant in the PBF process, 
whereas in electron beam melting EBM the kinetic energy of electrons is transferred into heat during the interaction with the powder material. Both can be used for manufacturing high precision parts. However, electron beam-based systems are rare and therefore not thoroughly introduced here.

The laser beam is focused and guided on the surface of a metal-powderbed, which is inside of a building (manufacturing) chamber, filled with inert gas (L-PBF), $\mathrm{N}$ or Ar, or a vacuum (EB-PBF/some L-PBF systems). Once the predefined areas of the powder-bed are melted, a machineintegrated recoater, or roller, will automatically spread another thin, typically $20-90 \mu \mathrm{m}$, powder layer on top of the previous one and the building platform goes down (is lowered) by as layer thickness and the process is repeated. The energy density of the laser beam must be high enough for sufficient melting and making the melt pool deep enough to reach the previously melted layer (solid). Some part of the beam reflects away from the powder bed, whilst a large part of it is absorbed by the material and melts it. The absorption of the powder is significantly higher on the powder bed than on a flat surface of solid metal, due to multiple reflections of the beam and large specific surface area of the powder material [23, 32]. When the beam moves on the bed, molten material is solidifying "behind" the beam and cooling down. Since the thermal cycle is very fast, also the solidification and cooling rates are high $[37,38]$. High cooling rate applies to L-PBF and causes a significantly different microstructure from the conventionally manufactured counterparts to form [23]. Imperfections, such as undesired microstructures, high residual stresses, and porosity can occur in powder-bed fusion [28]. During the process, at any particular time of melting, some parts of the work-piece are contracting during cooling, while others are expanding when heated. Cyclic heat delivery is inherent in L-PBF and it induces residual stresses to the parts, because of subsequent thermal expansions and contractions. These residual stresses can rise so high that eventually they can lead to bending and distortions within the part $[32,39]$.

Many system producers use their own commercial names for PBF such as selective laser sintering (SLS), direct metal laser sintering (DMLS), selective laser melting (SLM), laser cusing, or electron beam melting (EBM). Despite the word "sintering" in the names of some systems or processes, the current metal PBF systems completely melt the particles instead of sintering them [32], whereas in the PBF of polymers, the particles are either fused or sintered [40]. The number of different PBF 
system-producers is more than thirty. The system-producers and their machine base prices are published in an annual report by Wohlers Associates [24]. The average prices for these systems are presented in Table 2. However, total investment costs for a state-of-the-art mid-size L-PBF system and the required auxiliary equipment is closer to one million, than half a million euro.

L-PBF has developed a lot during the last twenty years. In the early 2000's, the machines started to be equipped with new, at the time just matured, fiber lasers. The efficiency of a fiber laser is much higher than that of the previously used $\mathrm{CO}_{2}$ lasers, which increased resolution and accuracy of the process remarkably. This was a major improvement, based on the improvement of beam quality, availability of cheaper and higher quality optics, simpler arrangement of the optical path, and the improved absorptivity of the laser beam to the metallic material, all enabled by utilization of fiber laser. In the late 2000's, the power of the lasers in L-PBF systems was increased to some hundreds of watts, and in the early 2010's, multi-laser systems were introduced. The number of lasers used and their power have both increased since then. Most of the models of different system-producers operate with one to four lasers in within the 100-1000 watt power-range. The cost of an additional laser in a system is typically less than the benefit achieved by improvement of productivity. According to the web-pages of four large L-PBF system producers, the productionspeeds of their flagship models are between $100-171 \mathrm{~cm}^{3}$ per hour. The machines are equipped with two or four 400,500 , or $700 \mathrm{~W}$ lasers [41-44]. Parameters guaranteeing the highest production-speeds are not disclosed and therefore it might be that these values do not correlate with normal manufacturing speeds or with best achievable accuracies. For example, increasing layer thickness has a major positive effect on building time and negative effect on accuracy. Therefore, an unambiguous value for

Table 2 Calculated average maximum build volume and average prices for L-PBF systems, based on data available in annual report by Wohlers Associates [24]

\begin{tabular}{llll}
\hline L-PBF system & Build volume (liters) & Average build volume (liters) & Average price (K€) \\
\hline Average system & 20 & - & $\sim 500$ \\
Small system & $<10$ & 1.5 & $\sim 200$ \\
Medium system & $10-30$ & 20 & $\sim 400$ \\
Large system & $>30$ & 70 & $\sim 1000$ \\
\hline
\end{tabular}


the volume rate, or the cost per kilogram cannot be stated due to "problem complexity" - the same applies for machining. However, a rough idea of the costs can be introduced. Volume-rate of one of the most common state-of-the-art mid-size AM system is approximately $15.2 \mathrm{~cm}^{3}$ per hour for one of the most common steel materials [45]. Diegel et al. [46] estimates that a 650,000 USD investment on an AM system leads to an hourly running cost of 48.69 USD. According to these numbers, a hourly machine running cost of constructing a theoretical one liter of solid steel would alone be $\sim 3200$ USD via L-PBF AM. This result to about 400 USD $/ \mathrm{kg}$, but it needs to be noted that this cost excludes, for example, the margin of the manufacturer, the labor, and the materials-related costs.

As mentioned, PBF is possibly the most evolved AM technology, but the production speed is still slow and the production is expensive compared to conventional manufacturing-furthermore the parts are usually semi-finished products that require post-processing $[32,35,36]$. However, the systems are developed constantly and new system-integrators are appearing on the market. The traditional system vendors are also coming to the additive manufacturing markets with new concepts. The competition is getting tougher since these traditional vendors have a consistent existing customer-base among the manufacturing companies.

\section{Other Metal Additive Manufacturing Technologies}

Directed energy deposition (DED) is another important method for metal additive manufacturing. The principle of the method is totally different from powder-bed fusion. The method is based on dynamically feeding material into the molten pool created with a heat source. The material can be in form of powder or wire, whereas the heat source to melt material is a laser beam, an electron beam, or an electric arc. The processes have their own descriptive names under the category of DED by ASTM. The laserbased process is typically called Laser Metal Deposition (LMD), electron beam-based Electron Beam Melting (EBM), and arc source-based Wire Arc Additive Manufacturing (WAAM).

The major differences between DED processes and the PBF are accuracy, building speed and build volume. Accuracy being better in case of PBF, whereas the building speed and the build volume are major advantages of the DED processes. DED processes are also typically capable of 
handling much higher heating power than PBF. DED processes can utilize high power with high building speed; typical laser power used is $1-4 \mathrm{~kW}$. The major difference of DED compared with PBF is the size of the part, which in case of PBF is restricted by the size of building chamber (typical sizes are reported above). Building volume can be several meters in each direction in case of DED, depending on the dimensions of the working area of the robotic system used. The accuracy on the other hand is typically around $0.1 \mathrm{~mm}$ for robotic systems and especially in the case of WAAM the accuracy is considerably lower.

The surface quality of DED parts is of a lower standard than that of the PBF process. This is typically, because of larger molten pool volumes and the dynamically fed material. In case of WAAM there is typically a lot of spattering leaving spatters on top of previously build parts. In case of powder LMD some of the powder is hitting the solidifying surface of melt pool and sticking there and melting only partially. In order to reach typically accepted part surface quality levels, all visible surfaces must be machined prior to further use. The utilization of DED is increasing at a considerable speed among manufacturers of larger components, where they have some specific areas of application, for example, in building shapes on top of a sheet structure to reach some of the advantages in design with reasonable pricing. Similar case is especially true with WAAM technology, which has appeared only during the last 2-3 years, even though the technology has been available for tens of years. WAAM techology is predicted to make only some percentages of the metallic printing market, but many conventional companies are interested in it, because they are already familiar with the technology from the perspective of welding.

Other metal AM methods exist, but they are relatively new processes, without many existing system-producers and without a significant number of scientific results published about them. Material extrusion of metals has expanded a lot during the last couple of years, but cannot produce as highquality parts as powder-bed fusion is capable of producing. The same applies to binder jetting of metal parts. Parts made with these processes have a remarkable lack in density, which leads to worse mechanical properties. On the other hand, total investment costs of both methods are lower than in the case of powder bed fusion. 


\section{Technology Readiness Level}

The entrance of a new technology to an existing technical environment is typically difficult. In practice, the new technology should be better and cheaper than existing technologies that have proven their position in the market. This is typically true within manufacturing, where there are often tight requirements in respect of mechanical properties and performance for part manufacture. The entrance of a new manufacturing technology is often very difficult because of this. Thus, there have not been real newcomer technologies, unless of the laser-based AM technologies are counted. The validation of a new technology is typically based on the existing technologies. A typical way to evaluate the state-of-the-art and capability of technology is assessment of so-called Technology Readiness Level (TRL). This evaluation scale is originally developed by NASA and is currently spreading to new applications. TRL scale is nine steps from introduction of technology to final accepted level where full utilization of technology can be carried out $[1,48]$ :

1. Basic manufacturing implications identified.

2. Manufacturing concept identified.

3. Manufacturing proof of concept developed.

4. Technology validated in laboratory environment.

5. Basic capabilities shown (near production environment).

6. System produced (near production environment).

7. Production in production environment demonstrated.

8. Pilot line capability demonstrated.

9. Low rate production.

10. Full rate production.

Because of the constant development-work carried out in technology and application level, various AM technologies and applications are in different TRL-levels. Some of the applications are already in TRL level 10, this includes applications within the aviation industry. An example of how a TRL-process goes forward is heat exchangers developed for NASA using Ultrasonic Additive Manufacturing 3D metal printing and elevated Ultrasonic Additive Manufacturing (UAM), a sheet lamination process. The company "Fabrisonic" reached TRL level 3 (proof of concept) and then TRL level 6 (prototype demonstrated in relevant environment) in 
2018. The company has successfully completed all tests required by NASA JPL for flight qualification [49].

\section{On the New Possibilities AM Offers}

Additive manufacturing enables multiple benefits in manufacturing parts compared to traditional manufacturing methods. Due to the layer-perlayer manufacturing process, AM allows the placement of material only to the areas required, which saves material and results in lighter parts $[3,31]$. By using advanced design and modeling software this freedom can be highly utilized due to the possibility to design complex AM parts that are as strong as, or even stronger than traditionally manufactured parts $[24,27]$.

In engineering, parts are often joined to form a larger assembly. AM reduces the need to join parts, as the joints can be integrated into the part. This means that complex piping can be built in a single piece without the need of making separate pipes and joining them together later by, for example, welding or mechanically by bolts. However, AM does not necessarily remove the need to join parts, because of the limited building volumes available.

AM opens new possibilities to tailor products for users. In general, AM is a single-step manufacturing process in which the part is built layer-bylayer typically on an empty platform with one machine, and thus the effort put in the manufacturing process itself is minimal compared to multi-step manufacturing methods such as casting and multi-round machining [24]. Due to the single-step process, small batches or single parts can be made more effectively than with conventional manufacturing methods. Also, the higher degree of freedom in AM compared to conventional manufacturing methods enables more unique shapes and products to be made [24, 31, 47].

AM is well-suited to allow the optimization of flow and heat characteristics of parts. Enhanced gas or fluid flow properties can be achieved, for example, with the possibility to manufacture smooth cavities with no sharp turns or corners. Enhanced heat-flow properties can be achieved by making large surface areas to, for example, heat exchangers [24, 31].

AM provides an opportunity to reduce the number of agents in a logistic chain, because a part can be printed with one machine without the need of molding or tooling. This is beneficial especially in the cases, where the part is printed in a single-step AM process and does not require further 
processing. AM also makes it possible to manufacture spare-parts for which the original tooling, molds, or production machines no longer exist $[24,27,47]$.

The future of AM materials is predicted to experience a noteworthy change. In case of metals, the process is totally different from the conventional steel making and features like local metallurgy are going to provide completely new alloys [22]. The current selection of available materials reflects the needs of current optimized metal manufacturing processes and there is a lot of potential for new commercial materials specific to AM. One possibility, which is currently studied in various locations, is that the small molten pool size typical for the PBF process enables much wider use of alloying elements than traditional manufacturing [10]. This can lead to an era of totally new materials with new sets of properties. AM differs from conventional manufacturing in the way that it does not utilize bulk material of which he geometry is modified, but also enables the modification of the microstructure. This means that microstructure is basically created during the printing process and AM equipment and systems do it differently [24]. For example, AM process-parameters and location of a part in building platform have a huge effect on cooling rates for any geometry. In conventional manufacturing, microstructures of parts are not changed during machining, but they can be controlled and modified by different standardized heat treatments performed after the processing. In AM, different heat treatments are part of the manufacturing process itself, but also separate heat treatments are applied to parts afterwards. One possibility of future of AM is the ability to control the heat treatments during the process to produce desired microstructure on demand [24].

\section{Challenges for AM}

Additive manufacturing has been said to completely revolutionize manufacturing or even being the fourth industrial revolution. The said manufacturing revolution of AM would unfortunately require that any components in any geometry could be manufactured in a single-step manufacturing process requiring no, or lower operator skills, and no assembly and resulting in a more cost-effective solution than the current manufacturing processes. AM can already produce some end-use metal components in a single-step process, but the area of these applications is very narrow and is limited mainly to prototypes. The restrictions come from the already mentioned surface quality and the degraded dimensional 
control that do not have a large role in prototyping. The dimensional control can be seen as manageable, once AM related software are developed enough, but there is no technology on the horizon for solving the surface quality issues in a single-step manufacturing process without adding other technologies to AM systems. In many goods, a lower surface quality would be sufficient enough, but "unfortunately" certain surface quality-levels have already been adopted as standard. On the other hand, most goods require better surface quality than what can be achieved via single-step additive manufacturing process. Worse surface quality means a larger surface area and that in turn means, for example, a larger area for bacteria and other impurities to fasten to and makes their removal harder. In mechanical engineering, certain tolerances are unavoidable and unfortunately outside the achievable scope of the dimensional accuracies of current additive manufacturing systems - later on higher accuracies become possibly achievable via more developed software that can predict output geometries better and scale models accordingly. At this stage, additive manufacturing of parts that can meet high tolerances require multiple iteration steps that result in inefficient cost structures. A lot of effort has been put on AM production of spare-parts, but unfortunately mentioned restrictions of the process makes many of these projects only conceptual studies without economic viability. However, a competitive company must stay on top of technology development and in order to stay competitive one must be active already when a technology reaches the breakthroughpoint-not after.

To date it is hard to state that AM would be more than an addition to the repertoire of available manufacturing methods. One can wonder whether AM could revolutionize manufacturing in the future and there is some truth to that kind of thinking, but at this stage there is no technology on the horizon to solve the already mentioned restrictions related to the AM process itself. In the 1990's, it was relatively easy to predict the future importance of the Internet as only the infrastructure was missing. The technology was already there but was expensive. For example, in metal additive manufacturing, the required technology is not here yet, nor is it on the horizon. In theory, a machine that could combine many different manufacturing methods leading to a machine that can build almost anything in a single-step process, would be the solution, but AM will probably not have major role in such a machine.

The most advanced metal AM processes are based on micro-scale laser welding and have the same limitations as "conventional" laser welding. 
Laser welding is highly studied and utilized in the most advanced manufacturing industries, but still cannot have welding speeds higher than what is specific for certain resolution due to dynamics of melt pools. The same applies to metal AM; the process speed of the laser cannot be increased without limits and are already operating at limit, as we know them. In the same way, the power of lasers cannot be increased limitlessly, because the higher the power density the lower the resolution. Number of lasers used can, and has been increased and multi-laser system have been on the market for a couple of years already, but single laser systems are still market leaders.

Another issue is that many different quality of products can be additively manufactured. The most common machines are the so called lowcost consumer 3D-printers, of which producible parts-quality does not represent the quality that an industrial high-end AM system is able to produce. Some people see only AM parts made with these low-cost machines and seem to have the notion that they are reflective of the capabilities of the additive manufacturing technology as a whole. These kinds of wrong impressions tend to slow down companies' adoption- and utilization levels of additive manufacturing.

A very common statement in the field of AM is that AM has no limitations in geometry or that design freedom exists in AM. It is possible to produce geometries that for example are not possible with CNC machining, inner structures are a good example of these. But the statement is only partially true, because on the other hand, AM, and especially metal AM lacks the possibility to create even some of the simplest geometries, like precise cubes and balls, or the so-called unsupported geometries. Cubes include sharp corners that have stress concentration and when a cube is large enough the too-large surface to be melted may lead to cracking of the metal. Ball shaped structures includes unsupported areas and if large enough are impossible to build without separate support structures and without heat sinks used to dissipate the heat away from the largest surface areas (to avoid excessive distortion caused by narrow contact area to the building platform). Hollow structures always mean that unsupported overhanging structures exist, which leads to the unavoidable need of support structures. Removal of support structures, for example, from inside of a hollow cube is impossible without breaking the structure. In addition, unmelted powder remains inside hollow structures and needs a separate hole for removal. Creating of these holes, separate heat sinks, or support structures is not a problem from the manufacturability perspective, but 
they often increase the need for post-processing. Additional support, or heat sink structures, mean that extra metal is welded to the part and needs to be removed often leaving undesired rough surfaces to their original locations. All these additional, but in many cases mandatory, steps take metal additive manufacturing further away from being a single-step manufacturing process, which is said to be its main advantage. This means that the statements "unlimited design freedom", or "possibility to create any geometries" have a truth-value of less than one. One limiting factor in the widely discussed freedom of design in $\mathrm{AM}$ is also the available building volume [47]. For example, metal powder-bed fusion machines have an average building chamber volume of approximately 20 liters. Larger building volumes are available, but they are rare because of remarkably higher investment costs involved, which lead to even higher machine hourly running costs [24]. Increased productivity covers the excess costs only, if the building volume is fully utilized in each manufacturing run. As mentioned, the PBF technology is a remarkably slower manufacturing method compared to conventional methods, as it is not capable of adding material at the same speed as machining is capable of removing it from a solid work piece [3]. Due to the slow building speed, the machine running costs usually climb high especially in tall builds. A build taller than $200 \mathrm{~mm}$ can take more than a hundred hours to construct.

\section{Future Trends and Development}

Regarding AM technology, the major trends are increasing the building speed, freedom in design, and the level of automation [47]. For example, the current use of a typical mid-size, mid-cost metal L-PBF machine requires a lot of manual work for filling and unpacking powder and for loading and unloading the building platform. Also moving the building platform from the printer, for example, to an oven for thermal treatment, and from there to a band saw for part removal is not a comfort for the machine operator. Support structure removal is currently a manual process, especially in connection with complicated parts that have support structures in locations unreachable with CNC tools [24]. There are existing projects that aim to replace the manual working phases with automation. The filling, unpacking, and recycling of the powder used is automatically done in some machines. Also, systems that have integrated thermal treatment within the machine are available. In the future, the automation level can be expected to spread into all manufacturing phases 
in such a way that the role of the machine operator will become that of supervisor [47].

Building speed is a major limitation of the L-PBF process and systemmanufacturers are constantly developing methods to increase it. For example, multi-laser systems, multi-recoater systems, and multi-direction recoater systems have been used to increase the building speed. However, the building speed is not yet satisfying for all needs, because AM is "always" compared to other manufacturing methods that are remarkably faster in most cases [47]. In some AM technologies such as vat photopolymerization, the building speeds have been increased to a level in which parts can be built in minutes.

Also new technologies arise within the AM realm. For example, the so called cold spray technology aims to tackle the limitations of building speed in metal AM by spraying metal powder particles with high speed to the desired locations in order to form a 3D-part. When the particles hit the building platform or the previous layer of the part, their kinetic energy transforms into heat and the particles melt on top of the previous layer [50]. This technology is claimed be 100-1000 times faster than the traditional metal AM.

Improvements in post-processing of metal parts are also being developed. The required support structures in metal L-PBF are a major restriction for the freedom of design [24], and thus, systems that focus purely on post-processing, are developed. For example, there are systems that are removing support structures automatically without mechanical work. The process works by "electrochemical pulse methods, hydrodynamic flow, and particle assisted chemical removal" according to one manufacturer. The problems with the support structures are also being solved from another point of view-to reduce the volume of needed support structures. New technology improvements allow the construction of parts in lower angles without support structures, but this does not eliminate the need of support structures completely; currently the parts must be at least anchored to the building platform $[24,31]$.

The quality of parts, especially metal parts, is a hot topic in AM. Process monitoring can be found from many L-PBF machine manufacturers' machines nowadays, but they are being developed for better performance to meet the quality assurance desires. The future trend is to develop systems, where process monitoring can detect a fault in the build and react to fix it during the next few layers. Since the nature of the PBF process is based on melting also some of the previous layers, corrective actions can 
be taken during at least two layers that follow the layer with the fault. This opens a window of opportunity to react to flaws in time, if sensors and algorithms are developed to be good enough. These so-called adaptive systems, which are not yet available, could really remove the flaws during the build $[51,52,53]$.

\section{REFERENCES}

1. NASA-National Aeronautics and Space Administration, (2013)-NPR 7123.1B-NASA Procedural Requirements—Systems Engineering Processes and Requirements, USA, 2013.

2. ISO/ASTM 52900:2015 Additive manufacturing - General principles - Terminology.

3. Gibson I, Rosen D, Stucker B, (2015) Additive Manufacturing Technologies: 3D Printing, Rapid Prototyping, and Direct Digital Manufacturing. Second Edition. New York: Springer. 498 p.

4. Monzón M, Paz R, Ortega Z, Diaz N, (2019) Knowledge Transfer and Standards Needs in Additive Manufacturing. In: Additive ManufacturingDevelopments in Training and Education. First edition. Cham: Springer International Publishing. 228 p.

5. Wohlers T, Campbell I, Diegel O, Kowen J, Fidan I, Bourell D L, (2018) Wohlers report 2018. 3D printing and additive manufacturing state of the industry annual worldwide progress report. $342 \mathrm{p}$.

6. Tofail S, Koumoulos E, Bandyopadhyay A, Bose A, O'Donoghue L, Charitidis C, (2018) Additive manufacturing: scientific and technological challenges, market uptake and opportunites. Materials Today 21(1): 23-37.

7. Schulze E, (2019) Everything you need to know about the Fourth Industrial Revolution. CNBC. Internet document. Cited: 27.1.2020. https://www. cnbc.com/2019/01/16/fourth-industrial-revolution-explaineddavos-2019.html.

8. European Patent Office, (2017) Patents and the Fourth Industrial Revolution: The inventions behind digital transformation December 2017. Internet document. Cited 27.1.2020. Available: http://documents.epo.org/projects/babylon/eponet.nsf/0/17FDB5538E87B4B9C12581EF0045762F/\$File/ fourth_industrial_revolution_2017_en.pdf.

9. Wellener P, Shepley S, Dollar B, Laaper S, Manolian H A, Beckoff D, (2019) 2019 Deloitte and MAPI Smart Factory Study. A report from Deloitte's research center for energy \& industrials group. Deloitte. 21 p. Cited 30.1.2020. https://www2.deloitte.com/content/dam/insights/us / articles/6276_2019-Deloitte-and-MAPI-Smart-Factory-Study/DI_2019Deloitte-and-MAPI-Smart-Factory-Study.pdf. 
10. Poprawe R, (2018) Digitale Photohiche Production-Die Zukunft der LaserMaterialarbeitung. Proceedings of 18th Laser Technology Congress AKL, Aachen, Germany, May 2th-4th 2018, Fraunhofer Institute for Laser Technology.

11. World Economic Forum, (2019) The Fourth Industrial Revolution: what it means, how to respond. Research Agenda. Cited: 30.1.2020. https://www. weforum.org/agenda/2016/01/the-fourth-industrial-revolutionwhat-it-means-and-how-to-respond/.

12. Statista, (2019) Internet of Things (IoT) connected devices installed base worldwide from 2015 to 2025. Cited 30.1.2020. https://www.statista.com/ statistics/471264/iot-number-of-connected-devices-worldwide.

13. Niaki M K, Nonino F, (2018) The Management of Additive Manufacturing: Enhancing Business Value. Cham: Springer International Publishing. 220 p.

14. Muthu S, Savalani M, (2016) Handbook of Sustainability in Additive Manufacturing, Vol. 2. Singapore: Springer. 114 p.

15. Huang R, Riddle M, Graziano D, Warren J, Das S, Nimbalkar S, Cresko J, Masanet E, (2016) Energy and emissions saving potential of additive manufacturing: the case of lightweight aircraft components. Journal of Cleaner Production 135(1): 1559-1570.

16. Townsend A, Senin N, Blunt L, Leach R K, Taylor J, (2016) Surface texture metrology for metal additive manufacturing: a review. Precision Engineering 46: 34-47.

17. Raaka-ainekäsikirja 5: Alumiinit, (2002) Tampere: Metalliteollisuuden Keskusliitto, MET. 235 p. Raaka-ainekäsikirja -sarja. MET-julkaisuja nro. 13/2002. [Handbook of Raw Materials 5: Aluminums] (in Finnish).

18. Ashby M F, Brechet Y J M, Cebon D, Salvo L, (2004) Selection strategies for materials and processes. Materials \& Design 25(1): 51-67.

19. Miekk-oja H M, Lindroos V, Sulonen M, Veistinen M, (1986) Uudistettu Miekk-ojan metallioppi. Teknillisten tieteiden akatemia: Otava Helsinki. 841 p. [Renewed edition of science of metals] (in Finnish).

20. Smith P, Rennie A, (2010) Computer aided material selection for additive manufacturing materials. Virtual and Physical Prototyping 5(4): 209-213. https://doi.org/10.1080/17452759.2010.527556.

21. Herzog D, Seyda V, Wycisk E, Emmelmann C, (2016) Additive manufacturing of metals. Acta Materialia 117: 371-392.

22. Weisheit A, (2018) Materials engineering for laser additive manufacturing. Proceedings of 18th Laser Technology Congress AKL, Aachen, Germany, May 2th-4th 2018, Fraunhofer Institute for Laser Technology.

23. Sun, S., Brandt, M., Easton, M., (2017) Powder bed fusion processes: an overview. Laser additive manufacturing: Materials, design, technologies, and applications. Pp. 55-79. 
24. Wohlers T, Campbell I, Diegel O, Kowen J, Huff R, (2019) Wohlers Report 2019. Fort Collins: Wohlers Associates, Inc. 369 p.

25. Schmidtke K, Palm F, Hawkins A, Emmelmann C, (2011) Process and mechanical properties: applicability of a scandium modified $\mathrm{Al}$-alloy for laser additive manufacturing, Phys. Procedia 12: 369-374.

26. Palm F, Schmidtke K, Exceptional grain refinement in directly built up Sc-modified AlMg-alloys is promising a quantum leap in ultimate light weight design, Proc of the 9th Int Conf Trends in Welding Research, June 4th-8th 2012, Chicago, USA, 108-115.

27. Yang L, Hsu K, Baughman B, Godfrey D, Medina F, Menon M, Wiener S, (2017) Additive Manufacturing of Metals: The Technology, Materials, Design and Production. Cham: Springer. $168 \mathrm{p}$.

28. Kurzynowski T, Gruber K, Stopyra W, Kuźnicka B, Chlebus E, (2018) Correlation between process parameters, microstructure and properties of $316 \mathrm{~L}$ stainless steel processed by selective laser melting. Materials Science and Engineering 718: 64-73. https://doi.org/10.1016/j.msea.2018.01.103.

29. Qian M, (2015) Metal powder for additive manufacturing. Minerals, Metals \& Materials Society 67(3): 536-537. https://doi.org/10.1007/s11837015-1321-z.

30. Wei L, Ehrlich L, Poweill-Palm M, Montgomery C, Beuth J, Malen J, (2018) Thermal conductivity of metal powders for powder bed additive manufacturing, Additive Manufacturing 21: 201-208.

31. Brandt M, (2017) Laser additive manufacturing: Materials, design, technologies, and applications. Amsterdam: Elsevier. 498 p.

32. Milewski J, (2017) Additive Manufacturing of Metals: From Fundamental Technology to Rocket Nozzles, Medical Implants, and Custom Jewelry. Cham: Springer. $343 \mathrm{p}$.

33. Xjet, (2019) Technology. Internet document, Cited 16.1.2019. https:// xjet3d.com/technology/.

34. Vadlamannati S, Vipin S, Soumitra B, (2019) Metal Powder Based Additive Manufacturing Technologies-Business Forecast. n 3D Printing and Additive Manufacturing Technologies. First edition. Singapore: Springer. 311 p.

35. Cabrini M, Lorenzi S, Pastore T, Pellegrini S, Ambrosio E, Calignano F, Manfredi D, Pavese M, Fino P, (2016) Effect of heat treatment on corrosion resistance of DMLS AlSil 0Mg alloy. Electrochimica Acta. 206: 346-355.

36. Wei P, Wei Z, Chen Z, Du J, He Y, Li J, Zhou Y, (2017) The AlSil0Mg samples produced by selective laser melting: single track, densification, microstructure and mechanical behavior. Applied Surface Science 408: 38-50. https://doi.org/10.1016/j.apsusc.2017.02.215.

37. Bertoli U S, Guss G, Wu S, Matthews M J, Schoenung J M, (2017) In-situ characterization of laser-powder interaction and cooling rates through high-speed imaging of powder bed fusion additive manufacturing. Materials and Design 135: 385-396. 
38. Mukherjee T, Wei H L, De A, DebRoy T, (2018) Heat and fluid flow in additive manufacturing-Part II: Powder bed fusion of stainless steel, and titanium, nickel and aluminum base alloys. Computational Materials Science 150: 369-380.

39. Wu A S, Brown D W, Kumar M, Gallegos G F, King W E, (2014) An experimental investigation into additive manufacturing-induced residual stresses in 316L stainless steel. Metallurgical and Materials Transactions: A 45A: 6260-6270.

40. Drummer D, Medina-Hernández M, Drexler M, Wudy K, (2015) Polymer powder production for laser melting through immiscible blends. Procedia Engineering 102: 1918-1925.

41. Concept Laser, (2019) Brochure of X LINE 2000R. Internet document, Cited 15.1.2019. https://www.concept-laser.de/fileadmin/Machine_brochures/CL_X_LINE_2000R_DS_EN_US_4_vl.pdf.

42. EOS, (2019) EOS M400-4. Internet document, Cited 11.1.2019. https:// www.eos.info/systems_solutions/eos-m-400-4.

43. Renishaw, (2019) RenAM 500Q. Internet document, Cited 23.1.2019. https://www.renishaw.com/en/renam-500q\%2D\%2D42781.

44. SLM, (2019) SLM®800. Internet document, Cited 11.1.2019. https://slmsolutions.com/en/products/machines/slmr800/.

45. EOS, (2017) Material data sheet-EOS Maraging Steel MS1. Available: https://cdn.eos.info/ldeee2b550955632/b3615b80c80a/ MS-MS1-M290_Material_data_sheet_10-17_en.pdf.

46. Diegel, O, Nordin, A, Motte, D, (2019) A Practical Guide to Design for Additive Manufacturing. First edition. Singapore: Springer. 218 p.

47. Attaran, M, (2017) The rise of 3D printing: The advantages of additive manufacturing over traditional manufacturing. Business Horizons 60: 677-688.

48. Straub J, (2015) In search of technology readiness level (TRL) 10. Aerospace Science and Technology 46: 312-320.

49. Accelerating 3D manufacturing at RAPID + TCT, (2018) Manufacturing Engineering 160(4): 88-95.

50. Bagherifard S, Monti S, Zuccoli M V, Riccio M, Kondás J, Guagliano M, (2018) Cold spray deposition for additive manufacturing of freeform structural components compared to selective laser melting. Materials Science \& Engineering A 721: 339-350.

51. Senvol, (2019) Senvol database of industrial AM machines and materials. Internet document, Cited 30.1.2020. http://senvol.com/5_material-results/.

52. Larimian T, Borkar T, (2019) Additive Manufacturing of In Situ Metal Matrix Composites. In: Additive Manufacturing of Emerging Materials. Cham: Springer, 1-28.

53. Leary M, (2017) Surface roughness optimization for selective laser melting (SLM): accommodating relevant and irrelevant surface. Laser additive manufacturing: Materials, design, technologies, and applications. Pp. 99-116. 
Open Access This chapter is licensed under the terms of the Creative Commons Attribution 4.0 International License (http://creativecommons.org/licenses/ by $/ 4.0 /$ ), which permits use, sharing, adaptation, distribution and reproduction in any medium or format, as long as you give appropriate credit to the original author(s) and the source, provide a link to the Creative Commons licence and indicate if changes were made.

The images or other third party material in this chapter are included in the chapter's Creative Commons licence, unless indicated otherwise in a credit line to the material. If material is not included in the chapter's Creative Commons licence and your intended use is not permitted by statutory regulation or exceeds the permitted use, you will need to obtain permission directly from the copyright holder.

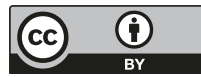

